FITRAH Jurnal Kajian Ilmu-ilmu Keislaman

Vol. 04 No. 1 Juni 2018

e-ISSN : 2460-2345, p-ISSN: 2442-6997

Web: jurnal.iain-padangsidimpuan.ac.id/index.php/F

\title{
PENDIDIKAN AGAMA BAGI ANAK DALAM KELUARGA DI GAMPONG ANEUK GALONG BARO, ACEH BESAR
}

\author{
AULIA RAHMI \\ Fakultas Agama Islam Universitas Serambi Mekkah Banda Aceh \\ Email:auliarahmiaceh@yahoo.com
}

\begin{abstract}
Religious Education in family environment is the education that's given by parent to their children in their family environment for building children's personality become a good muslim by changing their attitude and their behaviour that appropriate with Islamic Education. The aims of the study was to know parent's manner in training their children about religious in Gampong Aneuk Galong Baro. This research was conducted by using descriptive qualitative methode and the isntrument of the data was interview, observation and documentation. The finding of this study was revealed that religious education for children in family environment of gampong Aneuk Galong Baro was be begun with the aqidah education (aqidah is not attitude but the faith ), because aqidah (the faith) was the core of someone's basic faith that must be instilled to the children early. Furthermore, it was the worship education ( ibadah). In the worship education parents focus on teaching their children about praying, reading Holy Qur' an and also fasting. The last, parents teach their children about attitude (Akhlak) because the result of the faith and good worship, it can be seen in their daily attitude.
\end{abstract}

Keywoards: Religious Education, Children, Parents

\begin{abstract}
Abstrak
Pendidikan agama dalam keluarga adalah pendidikan yang diberikan orang tua kepada anaknya dalam lingkungan keluarga itu sendiri untuk membentuk kepribadian anak menjadi muslim dengan adanya perubahan sikap dan tingkah laku yang sesuai dengan ajaran islam. Tujuan dari penelitian ini adalah untuk mengetahui cara orang tua di gampong Aneuk Galong Baro dalam mendidik ilmu agama bagi anak-anaknya. Penelitian ini merupakan penelitian kualitatif deskriptif dengan instrumen penelitian yaitu wawancara, observasi dan dokumentasi. Adapun hasil penelitiannya menunjukkan bahwa pendidikan agama bagi anak dalam keluarga di gampong Aneuk Galong Baro dimulai juga dengan pendidikan akidah, karena akidah merupakan inti dari dasar keimanan seseorang yang harus ditanamkan kepada anak sejak dini. Selanjutnya dengan pendidikan ibadah, dalam pendidikan ibadah orang tua lebih memfokuskan kepada ibadah shalat, mengaji juga puasa. Terakhir orang tua mengajarkan anaknya tentang akhlak karena hasil dari keimanan dan ibadah yang baik dapat terlihat dalam akhlak sehari-hari.
\end{abstract}

Kata Kunci: Pendidikan Agama, Anak, Keluarga 
FITRAH Jurnal Kajian Ilmu-ilmu Keislaman

Vol. 04 No. 1 Juni 2018

\section{PENDAHULUAN}

Anak adalah anugerah sekaligus amanat yang diberikan Allah SWT. kepada setiap orang tuanya. Suatu hal yang tidak dapat dipungkiri bahwa kehadiran anak di tengah-tengah keluarga merupakan bagian terpenting dari kebahagiaan setiap rumah tangga. Anak dapat membuat senang hati kedua orang tuanya, manakala anak tersebut berbakti kepada mereka, serta taat dalam menjalankan ibadahnya. Namun anak juga dapat membuat susah kedua orang tuanya manakala anak tersebut tidak berbakti kepadanya, serta tidak taat beribadah. Ini semua tergantung bagaimana orang tua mendidik anaknya, karena sebelumnya anak dilahirkan dalam keadaan suci tidak mengerti apa-apa, sebagaimana Rasulullah saw bersabda :

$$
\text { قال النبي صلى الله عليه و سلم (كل مولود يولد على الفطرة فأبواه يهودانه أو ينصرانه أو يمجسانه }
$$

"Setiap anak dilahirkan dalam keadaan fitrah (Islam), maka kedua orang tuanyalah yang menjadikannya Yahudi, Nashrani atau Majusi." (HR. alBukhari\&Muslim)

Prof. Dr. Zakiah Darajat menyatakan bahwa perkembangan agama pada anak sangat ditentukan oleh pendidikan dan pengalaman yang dilaluinya, terutama pada masa pertumbuhan yang pertama (masa anak) dari umur 0-12 tahun. Untuk itu, orang tua harus menjadi pendidik yang paling bertanggung jawab terhadap perkembangan anaknya terutama dalam pembentukan akhlakul karimah, dalam lingkungan keluarga inilah anak pertama kali memperoleh pendidikan dan bimbingan. Setiap anggota keluarga mempunyai peran, tugas dan tanggung jawab masing-masing, dan mereka memberi pengaruh melalui proses pembiasaan pendidikan di dalam keluarga. Oleh karena itu kewajiban orang tua dalam memberikan pengetahuan agama yang mencakup ibadah maupun akhlakul karimah kepada anak-anak mereka.

Berdasarkan hal tersebut peneliti ingin mengetahui pendidikan agama bagi anak dalam keluarga yang berada di gampong Aneuk Galong Baro, apakah sudah sesuai berdasarkan suruhan Al-quran maupun sebagaimana yang di contohkan oleh rasul, karena pengetahuan agama anak sangat berpengaruh terhadap sikap mereka dalam kehidupan sehari-hari. 


\section{METODE PENELITIAN}

Dalam penelitian ini peneliti menggunakan Non-Probability Sampling merupakan teknik pengambilan sampel tidak dipilih secara acak. Unsur populasi yang terpilih menjadi sampel bisa disebabkan karena kebetulan atau karena faktor lain yang sebelumnya sudah direncanakan oleh peneliti. Teknik pemilihan sampel yang peneliti gunakan adalah purposive sampling.

\section{HASIL PEMBAHASAN}

\section{Pendidikan Agama Dalam Keluarga}

Menurut Syaiful Sagala pendidikan adalah segala situasi hidup yang mempengaruhi pertumbuhan individu sebagai pengalaman belajar yang berlangsung dalam segala lingkungan dan sepanjang hidup. Muhammad Daud Ali (1995) berpendapat bahwa pendidikan adalah usaha sadar yang dilakukan oleh manusia untuk mengembangkan potensi manusia lain atau memindahkan nilai-nilai yang dimilikinya kepada orang lain dalam masyarakat. Sedangkan Munardji menyatakan bahwa pendidikan adalah suatu proses penanaman sesuatu ke dalam diri manusia.

Berdasarkan beberapa keterangan di atas dapat disimpulkan bahwa pendidikan adalah usaha pendidik untuk membimbing peserta didik menuju akhlak yang baik.

Pendidikan Islam yaitu kegiatan yang berusaha mencari arif untuk menanamkan doktrin akidah dalam setting sosial yang beragam bentuk latar belakang kulturnya tanpa harus merusak akidah sehingga akidah dapat memberikan keharmonisan dalam kehidupan, dan tidak perlu adanya benturan antara akidah yang bersifat doktrin permanen dengan realitas sosial yang sifatnya kultural changeable (Djamaluddin, 2010:80). Sedangkan menurut Munardji pendidikan agama islam adalah bimbingan jasmani rohani berdasarkan hukum-hukum agama islam menuju terbentuknya kepribadian utama menurut ukuran islam.

Dari penjelasan diatas maka dapat disimpulkan bahwa pendidkan agama islam adalah usaha sadar yang dilakukan oleh generasi tua kepada generasi muda untuk membentuk pribadi yang islami. 
FITRAH Jurnal Kajian Ilmu-ilmu Keislaman

Vol. 04 No. 1 Juni 2018

Menurut Rohmat Mulyana keluarga merupakan unit terkecil dalam masyarakat, yang terdiri dari ayah, ibu, anak-anak, dan kerabat lainnya. Lingkungan keluarga merupakan tempat dimana anak-anak di besarkan dan merupakan lingkungan pertama kali dijalani oleh seorang anak dalam mengarungi hidupnya, sehingga apa yang dilihat dan dirasakan oleh anakanak dalam keluarga akan dapat mempengaruhi pertumbuhan dan perkembangan jiwa seorang anak.

Djahiri. A. K menyatakan bahwa keluarga merupakan lingkungan pertama bagi setiap individu dimana dia berinteraksi. Dari interaksi dengan lingkungan pertama inilah individu memperoleh ciri-ciri dan unsur-unsur dasar dalam kepribadiannya. Juga dari situlah dia memperoleh akhlak, nilainilai, kebiasaan dan emosinya dan dengan itu dia merubah banyak kemungkinan-kemungkinan, kesanggupan-kesanggupan dan kesediaannya menjadi kenyataan dalam hidup dan tingkah laku yang tampak. Jadi keluarga itu bagi seorang individu merupakan simbol atas nilai-nilai yang mulia, seperti keimanan yang teguh kepada Allah, pengorbanan, kesediaan berkorban untuk kepentingan kelompok, cinta kepada kebaikan, kesetiaan, dan nilai-nilai lainnya yang mulia, yang dengannya keluarga dapat menolong individu untuk menanamkannya pada dirinya.

Jadi pendidikan agama dalam keluarga adalah pendidikan yang diberikan orang tua kepada anaknya dalam lingkungan keluarga itu sendiri untuk kepribadian anak menjadi muslim dengan adanya perubahan sikap dan tingkah laku yang sesuai dengan ajaran islam.

\section{Ruang lingkup pendidikan agama dalam keluarga}

Sering kali orang menyangka bahwa pendidikan agama dalam keluarga, adalah pemberian pelajaran agama kepada agama. Tapi anggapan seperti itu kurang tepat, karena yang dimaksud adalah pembinaan jiwa agama atau dengan kata lain pembinaan pribadi pada anak. Mendidik anak dimulai sejak lahir, dalam halini orang tua harus memperhatikan pokokpokok dasar ajaran sunah rasul. Mendidik dengan cara humanis akan lebih mengena terhadap keberhasilan pendidikan anak-anak. Dalam hal ini orang 
tua harus memberi contoh atau teladan terlebih dahulu dan bukan hanya memberikan perintah.

Dalam rangka membentuk anak yang shalih dan shalihah maka pokok-pokok yang harus diberikan adalah ajaran islam yang bersumber pada Al-quran dan sunah rasul. Secara garis besar dikelompokkan menjadi tiga, yaitu:

a. Pendidikan Akidah

Pendidikan Islam dalam keluarga harus memperhatikan pendidikan akidah Islamiah, dimana akidah itu merupakan inti dari dasar keimanan seseorang yang harus ditanamkan kepada anak sejak dini. Sejalan dengan firman Allah yang artinya:

Dan ingatlah ketika lukman berkata kepada anaknya di waktu ia memberi pelajaran padanya: Hai anakku janganlah kamu mempersekutukan Allah benarbenar merupakan kedhaliman yang besar,' (QS,luqman:13).

Ayat tersebut menjelaskan bahwa akidah harus ditanamkan kepada anak yang merupakan dasar pedoman hidup seorang muslim (Anwar, tt).

Dengan pendidikan akidah diharapkan seseorang mampu meyakini keesaaan Allah dan akan sungguh-sungguh melaksanakan apa yang menjadi ketentuan dengan penuh tanggung jawab.

b. Pendidikan Ibadah

Pendidikan ibadah merupakan kelanjutan dari pendidikan akidah. Keyakinan dan keimanan tidak akan sempurna tanpa pembuktian dalam kehidupan nyata. Aspek pendidikan ibadah ini khususnya pendidikan shalat disebutkan dalam firman Allah yang artinya;

"Hai anakku, dirikanlah shalat dan suruhlah manusia untuk mengerjakan yang baik dan cegahlah mereka dari perbuatan munkar dan bersabarlah terhadap apa yang menimpa kamu, sesungguhnya hal yang demikian itu termasuk diwajibkan oleh Allah,"'(QS. Luqman:17).

Menurut Zakiah pelaksanaan ibadah dalam keluarga dapat dilakukan dengan cara peneladanan dan ajakan dalam beribadah seharihari. Jika anak telah terbiasa shalat dalam keluarga maka kebiasaan tersebut akan terbawa sampai dewasa. Pendidikan shalat harus sudah anak terima dari orang tuanya sejak ia umur tujuh tahun. Pendidikan 
FITRAH Jurnal Kajian Ilmu-ilmu Keislaman

Vol. 04 No. 1 Juni 2018

mengaji al-quran juga harus diterapkan kepada anak secara rutin setelah shalat sebagai persiapan fisik dan intelektual, agar anak mampu menanamkan nilai-nilai keimanan yang kuat ${ }^{1}$.

c. Pendidkan Akhlak

Hasil dari keimanan dan ibadah yang baik dapat terlihat dalam akhlak. Pendidikan akhlak dapat dilakukan dengan melatih anak dan membiasakan melakukan hal-hal yang baik, menghormati kedua orang tua, bertingkah laku sopan baik perilaku keseharian maupun dalam bertutur kata. sebagai firman Allah yang artinya.

"Dan sederhanakanlah kamu dalam berjalan dan lunakanlah suaramu dan sesungguhnya seburuk-buruk suara adalah suara himar,"(QS.Luqman:19).

Mahmud, dkk dalam bukunya menyatakan bahwa pendidikan akhlak dalam keluarga antara lain:

1) Mengawali kegiatan dengan basmallah dan mengakhiri dengan hamdallah

2) Mendidik anak agar menggunakan tangan kanan untuk mengambil, memberi, makan serta minum.

3) Mendidik dan memberi teladan anak untuk berlaku sopan santun

4) Mendidik anak untuk menghormati.

Ketiga aspek pendidikan agama di atas merupakan bentuk kesatuan antara lain saling berkaitan dan tidak dipisahkan. Ketiganya harus dilaksanakan dengan baik agar tujuan pendidikan islam dalam membentuk dan menyiapkan individu yang mampu memahami, menghayati, dan mengamalkan ajaran islam dapat terealisasi.

\section{Kewajiban Keluarga Terhadap Pendidikan Anak}

Pendidikan dalam keluarga merupakan dasar atau pondasi dari pendidikan anak selanjutnya. Di dalam keluargalah tempat meletakkan dasa-dasar kepribadian anak yang masih muda, karenapada usia ini biasanya anak-anak sangat peka terhadap pengaruh lingkungan keluarga. Keluarga mempunyai peranan yang sangat penting dalam pendidikan anak,

${ }^{1}$ Mahmud dan dkk, Pendidikan agama islam dalam keluarga (Jakarta: Akademia Permata, 2013), hlm. 181. 
oleh karena itu orang tua sebagai pendidik utama dan pertama bagi anakanak, karena merekalah yang mula-mula dikenal oleh anak sejak lahir².

Keluarga merupakan lembaga pertama dalam kehidupan anak, tempat ia belajar dan menyatakan diri sebagai makhluk sosial. Keluarga memberikan dasar pembentukan tingkah laku, watak, moral melalui pendidikan ${ }^{3}$. Begitupun orang tua dalam bersikap atau bertindak menjadi patokan, sebagai contoh agar ditiru dan apa yang ditiru akan meresap dalam diri anak, dan menjadi bagian dari kebiasaan bersikap dan bertingkah laku atau bagian dari kepribadiannya. Orang tua menjadi faktor terpenting dalam menanamkan dasar kepribadian atau akhlak pada anak-anaknya.

Abdullah Nasih Ulwan dalam bukunya menjelaskan bahwa ada tiga kewajiban orang tua dalam memenuhi hak anak, seperti yang diceritak dalam kisah Umar bin Khaththab: Pada suatu kesempatan, Amirul Mukminin Umar bin Khaththab kehadiran seorang tamu lelaki yang mengadukan kenakalan anaknya, "Anakku ini sangat bandel." tuturnya kesal. Amirul Mukminin berkata, "Hai Fulan, apakah kamu tidak takut kepada Allah karena berani melawan ayahmu dan tidak memenuhi hak ayahmu?" Anak yang pintar ini menyela. "Hai Amirul Mukminin, apakah orang tua tidak punya kewajiban memenuhi hak anak?"Umar ra menjawab, "Ada tiga, yakni: pertama, memilihkan ibu yang baik, jangan sampai kelak terhina akibat ibunya. Kedua, memilihkan nama yang baik. Ketiga, mendidik mereka dengan al-Qur'an."Mendengar uraian dari Khalifah Umar ra anak tersebut menjawab, "Demi Allah, ayahku tidak memilihkan ibu yang baik bagiku, akupun diberi nama "Kelelawar Jantan", sedang dia juga mengabaikan pendidikan Islam padaku. Bahkan walau satu ayatpun aku tidak pernah diajari olehnya. Lalu Umar menoleh kepada ayahnya seraya berkata, "Kau telah berbuat durhaka kepada anakmu, sebelum ia berani kepadamu.

Seorang anak terlahir di atas fitrah, sebagaimana sabda Rasulullah maka sesuatu yang sedikit saja akan berpengaruh padanya. Dan wanita

${ }^{2}$ HM. Djumransjah dan Abdul Malik Karim Amrullah, Pendidikan Islam: Menggali tradisi mengukuhkan eksistensi (Malang: UIN Malang Press, 2007), hlm. 84.

${ }^{3}$ Kartono Kartini, Peran Keluarga Memandu Anak (Jakarta: Rajawali Press, 2002), hlm. 19. 
FITRAH Jurnal Kajian Ilmu-ilmu Keislaman

Vol. 04 No. 1 Juni 2018

muslimah senantiasa mendidik anak-anaknya dengan akhlak yang baik, yaitu akhlak Muhammad dan para sahabatnya yang mulia, serta menanamkan kecintaan tehadap agama ini kepada anak-anaknya.

a) Memberi contoh kepada anak dalam berakhlak mulia. Sebab orang tua yang tidak berhasil menguasai dirinya tentulah tidak sanggup meyakinkan anak-anaknya untuk memegang akhlak yang diajarkannya.

b) Menyediakan kesempatan kepada anak untuk mempraktikkan akhlak mulia.

c) Memberi tanggung jawab sesuai dengan perkembangan anak. Pada awalnya orang tua harus memberikan pengertian dulu, setelah itu baru diberikan suatu kepercayaan pada diri anak itu sendiri.

d) Mengawasi dan mengarahkan anak agar selektivitas dalam bergaul. Jadi orang tua tetap memberikan perhatian kepada anak-anak, dimana dan kapanpun orang tua selalu mengawasi dan mengarahkan, menjaga mereka dari teman-teman yang menyeleweng dan tempat-tempat maksiat yang menimbulkan kerusakan.

Pendidikan yang dilakukan oleh orang tua sangat menentukan baik dan buruknya kehidupan anak di masa mendatang. Suatu hal yang mustahil dalam pandangan islam bila seseorang yang tidak berhasil mendidik diri sendiri akan dapat melakukan pendidikan kepada orang lain. Oleh karena itu, sebagai orang tua harus pandai membimbing dan mendidik anaknya, sehingga tujuannya dalam mendidik anak dapat benar-benar terwujud.

Penelitian ini menggunakan pendekatan penelitian kualitatif yaitu penelitian yang bermaksud untuk memahami fenomena tentang apa yang dialami subjek penelitian. Secara holistik dengan cara deskripsi dalam bentuk kata-kata dan bahasa, pada suatu konteks khusus yang alamiah dan memanfaatkan berbagai metode ilmiah4. Tujuan kualitatif yaitu memahami fenomena sosial melalui gambaran holistik dan memperbanyak pemahaman yang mendalam ${ }^{5}$. Hal ini sesuai dengan karakteristik permasalahan yang

${ }^{4}$ L.J. Moleong, Metodologi Penelitian Kualitatif (Bandung: Rosda Karya, 2007), hlm. 6.

${ }^{5}$ L.J Moleong, Metodologi Penelitian Kualitatif. (Bandung: Remaja Rosdakarya, 2010), hlm. 31. 
hendak diungkap yaitu, bagaimana pendidikan agama bagi anak dalam keluarga di gampong Aneuk Galong Baro.

Adapun sumber data yang digali dalam penelitian ini terdiri dari sumber data utama yaitu dari wawancara dengan informan yang telah ditentukan dan data observasi, serta sumber data tambahan yang berupa dokumen-dokumen. Sumber data utama dalam penelitian kualitatif ialah kata-kata dan tindakan selebihnya merupakan data tambahan seperti dokumen dan sumber data yang lain. Jadi sumber data dalam penelitian ini adalah kata-kata yang diperoleh dari subyek penelitian, hasil observasi dan dokumen yang merupakan data tambahan.

\section{HASIL PENELITIAN}

Untuk membentuk anak yang shalih dan shalihah maka pokok-pokok yang harus diberikan adalah ajaran islam yang bersumber pada Al-quran dan sunah rasul. Secara garis besar dikelompokkan menjadi tiga, yaitu: pendidikan akidah, ibadah dan shalat. Berdasarkan hasil penelitian menunjukkan bahwa pendidikan agama bagi anak dalam keluarga di gampong Aneuk Galong Baro juga dimulai dengan pendidikan akidah, karena akidah merupakan inti dari dasar keimanan seseorang yang harus ditanamkan kepada anak sejak dini. Berdasarkan hasil wawancara dengan orang tua di gampong Aneuk Galong Baro tentang pendidikan akidah, mereka mengatakan bahwa "Anak-anak sudah diajarkan tentang akidah sejak anak-anak masih balita, dikenalkan kepada anaknya siapa Allah, malaikatNya, RasulNya, kitab kita apa dan kenapa harus mengerjakan perintah Allah. Karena dengan cara itu orang tua mengajarkan keimanan anak-anaknya kepada Allah".

Pendidikan ibadah shalat bagi anak dalam keluarga dimulai dengan orang tua mencontohkan langsung gerakan shalat ketika shalat, lama kelamaan anak akan meniru perbuatan orang tuanya ketika shalat. Namun tidak semua orang tua mengajarkan langsung bagaimana bacaan shalat kepada anakanaknya, anak-anak belajar bacaan shalat ketika mereka mulai pergi ke tempat pengajian. Kedisplinan anak-anak dalam mengerjakan kewajiban shalat juga kurang dari pengawasan orang tua sehingga banyak anak-anak yang sudah berumur sepuluh tahun belum menunaikan kewajiban shalat secara sempurna. Selain shalat, mengaji juga merupakan ibadah yang terpenting yang harus 
FITRAH Jurnal Kajian Ilmu-ilmu Keislaman

Vol. 04 No. 1 Juni 2018

dikerjakan. Sejak anak masih balita orang tua sudah mulai mengajarkan anaknya mengaji, sehingga ketika anaknya sudah mengaji ke tempat teungku si anak tidak perlu lagi di ajarkan dari iqra namun langsung ke alquran besar.

Pendidikan akhlak dalam keluarga di gampong Aneuk Galong Baro dilakukan dengan melatih anak dan membiasakan melakukan hal-hal yang baik seperti memberi salam ketika masuk ke rumah, makan menggunakan tangan kanan. Anak juga diajarkan untuk menghormati kedua orang tuanya dengan cara mendengar ucapan orang tua, tidak besar-besar suara kepada orang tua dan patuh. Orang tua juga mengajarkan anaknya bertingkah laku sopan baik perilaku maupun dalam bertutur kata dalam keseharian bermasyarakat. Orang tua akan menegur anaknya apabila berbuat salah, baik berbuat salah dengan keluarga maupun dengan masyarakat.

\section{PENUTUP}

Pendidikan agama dalam keluarga adalah pendidikan yang diberikan orang tua kepada anaknya dalam lingkungan keluarga itu sendiri untuk kepribadian anak menjadi muslim dengan adanya perubahan sikap dan tingkah laku yang sesuai dengan ajaran islam. Dalam rangka membentuk anak yang shalih dan shalihah maka pokok-pokok yang harus diberikan adalah ajaran islam yang bersumber pada Al-quran dan sunah rasul. Secara garis besar dikelompokkan menjadi tiga, yaitu: pendidikan akidah, ibadah dan pendidikan akhlak.

Hasil penelitian menunjukkan bahwa pendidikan agama bagi anak dalam keluarga di gampong Aneuk Galong Baro dimulai juga dengan pendidikan akidah, karena akidah merupakan inti dari dasar keimanan seseorang yang harus ditanamkan kepada anak sejak dini. Selanjutnya dengan pendidikan ibadah, dalam pendidikan ibadah orang tua lebih memfokuskan kepada ibadah shalat, mengaji juga puasa. Terakhir orang tua mengajarkan anaknya tentang akhlak karena hasil dari keimanan dan ibadah yang baik dapat terlihat dalam akhlak sehari-hari. Pendidikan akhlak yang dilakukan oleh orang tua di gampong Aneuk Galong Baro dengan cara melatih anak dan membiasakan melakukan hal-hal yang baik, menghormati kedua orang tua, bertingkah laku sopan baik perilaku keseharian maupun dalam bertutur kata. 


\section{DAFTAR PUSTAKA}

Derajat, Zakiah, Pendidikan Islam dalam Keluarga dan Sekolah, (Jakarta: Bumi Aksara, 1994)

Djahiri. A. K, Menelusuri Dunia Efektif, pendidikan Nilai dan Moral, Bandung: Lab. PMP IKIP; 1966)

Hasyim, Umar, Anak Sholeh (Cara Mendidik Anak dalam Islam), (Surabaya : PT Bina Ilmu, 2000)

HM. Djumransjah dan Abdul Malik Karim Amrullah, Pendidikan Islam: Menggali tradisi mengukuhkan eksistensi, (Malang: Uin Malang Press, 2007)

Idris, S \& Tabrani, Z. A. (2017). Realitas Konsep Pendidikan Humanisme dalam Konteks Pendidikan Islam. Jurnal Edukasi: Jurnal Bimbingan Konseling, 3(1), 96-113.

Kartono, Kartini, Peran Keluarga Memandu Anak, (Jakarta : Rajawali Press, 2002)

M.I. Seolaeman, Pendidikan dalam Keluarga. Diktat Kuliah; 1978

Mahmud, dkk, Pendidikan agama islam dalam keluarga, (jakarta: akademia permata, 2013)

Mulyana, Rohmat, Cakrawala Pendidikan Umum, Bandung: Ikatan Mahasiswa dan Alumni Pendidikan Umum (IMA-PU) PPS IKIP Bandung; 1999)

Muzayyin, Arifin, Filsafat Pendidikan Islam, Bumi Aksara, Jakarta, 2010.

Nufiar, N., \& Idris, S. (2016). Teacher Competence Test of Islamic Primary Teachers Education in State Islamic Primary Schools (MIN) of Pidie Regency. Jurnal Ilmiah Peuradeun, 4(3), 309-320.

Suzanne, R., \& Nathalie, L. (2016). Multiculturalism as an Alternative A Cultural Orientation to Education in the Aspect of Culture as the Axiological Focus. Jurnal Ilmiah Peuradeun, 4(3), 383-394.

Tabrani. ZA \& Masbur, M. (2016). Islamic Perspectives on the Existence of Soul and Its Influence in Human Learning (A Philosophical Analysis of the Classical and Modern Learning Theories). Jurnal Edukasi: Jurnal Bimbingan Konseling, 1(2), 99-112. 
FITRAH Jurnal Kajian Ilmu-ilmu Keislaman

Vol. 04 No. 1 Juni 2018

Tabrani. ZA. (2014). Islamic Studies dalam Pendekatan Multidisipliner (Suatu Kajian Gradual Menuju Paradigma Global). Jurnal Ilmiah Peuradeun, 2(2), 211-234.

Tabrani. ZA. (2014). Isu-Isu Kritis dalam Pendidikan Islam. Jurnal Ilmiah Islam Futura, $13(2), 250-270$

Tabrani. ZA. (2016). Perubahan Ideologi Keislaman Turki (Analisis Geo-Kultur Islam dan Politik Pada Kerajaan Turki Usmani). Jurnal Edukasi: Jurnal Bimbingan Konseling, 2(2), 130-146.

Ulwan, Abdullah Nasih, Pendidikan Anak dalam Islam, pentj. Jamaluddin Miri, (Jakarta: Pustaka Amani, 2002)

Walidin, W. (2016). Informal Education as A Projected Improvement of the Professional Skills of Employees of Organizations. Jurnal Ilmiah Peuradeun, 4(3), 281-294. 